\title{
PREVALENCE OF ANEMIA AMONG CHILDREN DIAGNOSED WITH PNEUMONIA ATTENDING BIRAT MEDICAL COLLEGE TEACHING HOSPITAL, MORANG, NEPAL.
}

\author{
Chandra Bhushan Jha ${ }^{1 *}$, Hem Sagar Rimal', Ram Bhakta Subedi
}

\section{Affiliation}

1. Assistant Professor, Department of Pediatrics, Birat Medical College and Teaching Hospital, Nepal

2. Professor and HOD, Department of Pediatrics, Birat Medical College and Teaching Hospital, Nepal

3. Lecturer, Department of Pediatrics, Birat Medical College and Teaching Hospital, Nepal

\section{ARTICLE INFO}

Received : 05 July, 2021
Accepted : 12 January, 2021
Published : 04 November 2021

(C) Authors retain copyright and grant the journal right of first publication with the work simultaneously licensed under Creative Commons Attribution License CC - BY 4.0 that allows others to share the work with an acknowledgment of the work's authorship and initial publication in this journal.

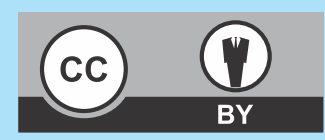

\section{ORA 267}

DOI: https://doi.org/10.3126/bjhs.v6i2.40356

\author{
* Corresponding Author \\ Dr. Chandra Bhushan Jha \\ Assistant Professor \\ Department of Pediatrics \\ Birat Medical College and Teaching Hospital, Nepal \\ Email:drcbjha8@gmail.com \\ ORCID: https://orcid.org/0000-0002-0738-9747
}

\section{Citation}

Chandra Bhushan Jha, Hem Sagar Rimal, Ram Bhakta Subedi. Prevalence of Anemia among Children Diagnosed with Pneumonia Attending Birat Medical College Teaching Hospital, Morang, Nepal. BJHS 2021;6(2)15. 1545-1548.

\section{ABSTRACT}

\section{Introduction}

Childhood pneumonia is the leading cause of serious illness and death worldwide. In developing countries, pneumonia is the biggest single cause of childhood death under the age of 5 years. Globally, anemia is a major nutritional problem of immense public health significance. Iron deficiency anemia in children occurs most frequently between the age of 6 months and 3 years, the same period of age when repeated infections occur.

\section{Objective}

The main objective of this study is to determine the prevalence of anemia among children diagnosed with pneumonia.

\section{Methodology}

This is a hospital based cross sectional study carried out in the Department of Paediatrics, Birat Medical College Teaching Hospital from $15^{\text {th }}$ February 2020 to $15^{\text {th }}$ August 2020. The physical finding such as: fever, tachypnoea, breathing difficulties, rhonchi, crackles, and wheezing were used to diagnose pneumonia. According to World Health Organization, the tachypnea thresholds to diagnose pneumonia are: in children between two and twelve months, 50 breaths per minute (Normal 25-40 breaths per minute); 40 breaths per minute in children between one and five years (Normal 20-30 breaths per minute). This study was performed on 150 pneumonic children between 6 to 60 months of age. History regarding fever, cough and fast breathing was taken. All the data were recorded in the preformed proforma. Data was analyzed using SPSS version 16.

\section{Result}

This study was performed on 150 pneumonic children, in which male babies ( $n=93 ; 62 \%$ ) outnumbered the female babies $(n=57 ; 38 \%)$. The majority of children were in the age group of 6 to 24 month $(n=85 ; 56.7 \%)$. The mean hemoglobin level was 9. $49 \pm 1.39 \mathrm{gm} / \mathrm{dl}$. The hemoglobin level less than 11 $\mathrm{gm} / \mathrm{dl}$ was seen in 102 (68\%) cases. Microcytic hypochromic anemia was present in $73(71.6 \%)$ children.

\section{Conclusion}

The prevalence of anemia among the pneumonic children of $6-60$ months is $68 \%$ that is higher than the national data (52.6\%) of prevalence of anemia in the same age group. While treating childhood pneumonia, checking hemoglobin on regular basis will be very useful to diagnose and manage concurrent anemia

\section{KEYWORDS}

Anemia, Hemoglobin, Pneumonia. 


\section{INTRODUCTION}

Childhood pneumonia is the leading cause of serious illness and death worldwide and it can be generally defined as inflammation of the lung parenchyma. ${ }^{1}$ In developing countries, pneumonia is the biggest single cause of childhood death under the age of 5 years. Globally each year there are about three million deaths, less than 5 years of age are due to pneumonia. Out of total deaths, 90 to $95 \%$ are in the developing countries.

Globally, anemia is a major nutritional problem of immense public health significance, affecting persons of all ages, sex and economic group. ${ }^{3}$ Various predisposing factors, including nutritional, genetic, and infectious disease factors are seen; however, iron deficiency causes $75 \%$ of anemia cases. ${ }^{4}$ An iron deficiency is frequently identified during the 6 months to 3 years which can be due to the loss of the iron stock taken from the mother during the last trimester of pregnancy and due to the lack of iron intake due to the food diversification and exploration period. ${ }^{5}$ The hemoglobin $(\mathrm{Hb})$ level is the most reliable indicator in the diagnosis of anemia among individuals. ${ }^{6}$

In the immune system, iron functions are essential, among which are: the maintenance of the activity of phagocyte oxidase; the increase of expression of the inducible nitric oxide synthase (iNOS). In the same way, intracellular iron promotes the activation of factor nuclear kappa B (NF-kB) and toll-like receptor 4 (TLR4) signaling. ${ }^{7}$ Therefore, there is an association between iron deficiency and a reduced immune response to infection. On the other hand, an iron excess can be used by bacteria to improve its growth. This association between iron and the immunological system could explain an increased risk of respiratory tract infection observed in children with iron deficiency anemia. ${ }^{8}$

Iron deficiency anemia in children occurs most frequently between the age of 6 months and 3years, the same period of age when repeated infections occur. Whatever may be the etiology of anemia is, the relation between low hemoglobin level and pneumonia has not been fully evaluated, and only few reports are available evaluating this subject. ${ }^{2}$

Detailed clinical examination and imaging may help in diagnosing pneumonia but clinical management is dependent on the predisposing factors associated with pneumonia. Thus, it holds a very important diagnostic significance. Significant morbidity or morbidity can be prevented if anemia as a risk factor associated with pneumonia is diagnosed early. The research findings may be useful for the pediatricians to make comprehensive management plan at an early stage while dealing with children with pneumonia. The main objective of this study is to determine the prevalence of anemia among children diagnosed with pneumonia.

\section{METHODOLOGY}

This is a hospital based cross sectional study carried out from $15^{\text {th }}$ February 2020 to $15^{\text {th }}$ August 2020 in the department of Paediatrics, Birat Medical College Teaching Hospital. Ethical clearance was obtained from the Institutional Review Committee (IRC) of the institute to carry out the study. The physical finding such as: fever, tachypnea, breathing difficulties, rhonchi, crackles, and wheezing were used to diagnose pneumonia. According to World Health Organization, the tachypnea thresholds to diagnose pneumonia are: in children between two and twelve months, 50 breaths per minute (Normal 25-40 breaths per minute); 40 breaths per minute in children between one and five years (Normal 2030 breaths per minute). ${ }^{8}$ The study was conducted on 150 children between the age of 6 month to 60 month with the clinical diagnosis of pneumonia. The informed written consent was taken from their parents. Parents of children unwilling to give consent, children with other systemic illness, those already received antibiotics from outside and with the diagnosis of concomitant conditions that could affect the anthropometric or hemoglobin parameters, or that could predispose to pneumonia were excluded. Hemoglobin level below $11 \mathrm{gm} / \mathrm{dl}$ was considered low in this study. The complete history and thorough physical examination were carried out in all the children. Complete blood count, mainly considering hemoglobin level and red blood cell indices were estimated. In red blood cell indices, mean corpuscular volume (MCV), mean corpuscular hemoglobin $(\mathrm{MCH})$, mean corpuscular hemoglobin concentration (MCHC) and red cell distribution width (RDW) were estimated to classify the type of anemia. Anemia was defined and classified according to WHO criteria and the severity of anemia according to patient's hemoglobin level (Severe anemia, $\mathrm{Hb}$ <7 gm/dl; moderate anemia, $\mathrm{Hb}$ 7-9.9 gm/dl; and mild anemia, $\mathrm{Hb} 10-10.9 \mathrm{gm} / \mathrm{dl}$ ). The data was recorded in a predesigned proforma and data analysis was done using statistical package of social science (SPSS) version 16. Numerical variables were reported in terms of mean and standard deviation. Categorical variables were reported in terms of numbers and percentages.

\section{RESULTS}

The present study constituted a total of 150 cases, in which male babies ( $n=93 ; 62 \%$ ) outnumbered the female babies $(n=57 ; 38 \%)$. The majority of children were in the age group of 6 to 24 month ( $n=85 ; 56.7 \%)$, and the remaining 65 (43.3\%) children between 25 to 60 month.

Cough, fever and fast breathing were the main symptoms

Table 1: Sociodemographic characteristics of the participants $(\mathrm{N}=422)$

\begin{tabular}{|c|c|c|}
\hline Variables & Number & Percentage (\%) \\
\hline $\begin{array}{c}\text { Gender } \\
\text { a. Male } \\
\text { b. Female }\end{array}$ & 93 & 62 \\
\hline Age & 57 & 38 \\
a. $\begin{array}{l}6-24 \text { months } \\
\text { b. } 25-60 \\
\text { months }\end{array}$ & 85 & 56.7 \\
\hline Total & 150 & 43.3 \\
\hline
\end{tabular}


observed in 150 (100\%), 121 (80.7\%) and 102 (68\%) children respectively. Among the signs and auscultatory findings, chest indrawing was present in 130 (86.7\%) and crepitations and wheeze in 111 (74\%) and 80 (53.3\%) cases respectively. (Table 2)

Table 2: Clinical features at presentation
\begin{tabular}{|l|l|c|}
\hline \multicolumn{1}{|c|}{ Symptoms } & Number & Percentage (\%) \\
\hline Fever & 121 & 80.7 \\
\hline Cough & 150 & 100 \\
\hline Shortness of breath & 75 & 50 \\
\hline Noisy breathing & 82 & 54.7 \\
\hline Fast breathing & 102 & 68.0 \\
\hline Signs & & \\
\hline Chest indrawings & 130 & 86.7 \\
\hline Wheeze & 80 & 53.3 \\
\hline Crepitations & 111 & 74 \\
\hline
\end{tabular}

The hemoglobin level less than $11 \mathrm{gm} / \mathrm{dl}$ was seen in 102 $(68 \%)$ cases and greater than $11 \mathrm{gm} / \mathrm{dl}$ was seen in $48(32 \%)$ cases. Therefore the prevalence of anemia in pneumonic children was $68 \%$ in our study. The mean hemoglobin level was $9.49 \pm 1.39 \mathrm{gm} / \mathrm{dl}$. (Table 3 )

Table 3: Hemoglobin level among pneumonic children

\begin{tabular}{|c|c|c|}
\hline Hemoglobin level (gm/dl) & Frequency & Percentage (\%) \\
\hline$<11$ & 102 & 68 \\
\hline$>11$ & 48 & 32 \\
\hline Total & $\mathbf{1 5 0}$ & $\mathbf{1 0 0}$ \\
\hline \multicolumn{2}{|l}{ Mean Hb level $9.49 \pm 1.39 \mathrm{gm} / \mathrm{dl}$} \\
\hline
\end{tabular}

Microcytic hypochromic anemia was present in 73 (71.6\%) children with mean MCV 61.8 femtoliters, mean MCH 19.2 picograms, mean MCHC $25.9 \mathrm{gm} / \mathrm{dl}$ and mean RDW $16.8 \%$. Normocytic normochromic anemia was seen in 29 (28.4\%) children. (Table 4)

Table 4: Anemia type based on red cell indices among anemic children.

\begin{tabular}{|l|c|c|}
\hline Anemia type & Frequency & Percentage (\%) \\
\hline Microcytic hypochromic anemia & 73 & 71.6 \\
\hline Normocytic normochromic anemia & 29 & 28.4 \\
\hline Total & 102 & 100 \\
\hline
\end{tabular}

$P$ value $<0.001$

The majority of anemic children, 64 (62.7\%) were in the age group of 6 to 24 month with $38(37.3 \%)$ being of 24 to 60 months. (Table 5)

Out of 102 anemic cases, 4 (3.9\%) belonged to $<7 \mathrm{gm} / \mathrm{dl}, 25$ (24.5\%) belonged to 7 to $9.9 \mathrm{gm} / \mathrm{dl}$ and $73(71.6 \%)$ belonged to 10 to $10.9 \mathrm{gm} / \mathrm{dl}$. (Figure 1 )

\begin{tabular}{|c|c|c|c|}
\hline & \multicolumn{2}{|c|}{ Hemoglobin level } & Total \\
\hline Age group & $<11$ & $>11$ & \\
\hline $6-24$ mth & $64(62.7 \%)$ & $21(43.8 \%)$ & $85(56.7 \%)$ \\
\hline 24-60mth & $38(37.3 \%)$ & $27(56.2 \%)$ & $65(43.3 \%)$ \\
\hline Total & 102 & 48 & 150 \\
\hline
\end{tabular}

\section{$P$ value $=0.022$}

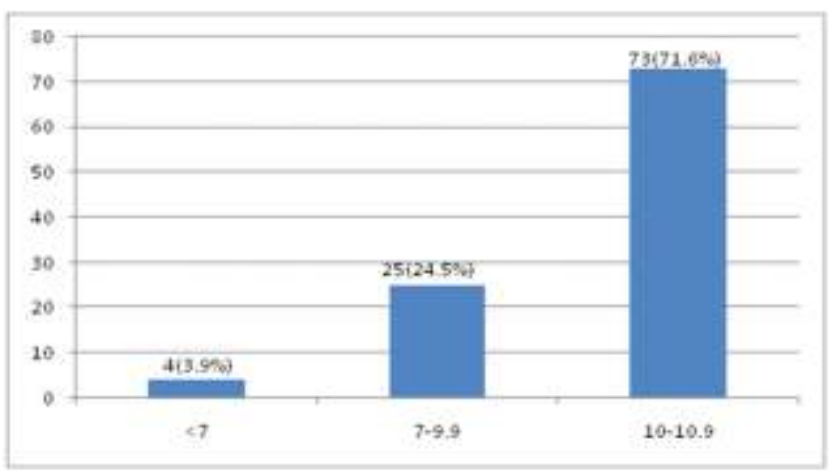

Figure 1: Classification of severity of anemia

\section{DISCUSSION}

Pneumonia is the leading single cause of mortality in children aged below 5 years. The incidence in this age group is estimated to be 0.29 episodes per child year in developing countries and 0.05 episodes per child per year in developed countries. ${ }^{1}$ In our study, a total of 150 children with pneumonia were included who met the inclusion criteria of our study.

In our study, 93(62\%) were male children and 57 (38\%) were female children which is similar to the study done by Rani et al and Sakellaropoulou et al who reported $51.7 \%$ and $59 \%$ male children with pneumonia respectively. ${ }^{1,9}$

In this study, 85 (56.7\%) children were of 6-to-24-month age group with 65 (43.3\%) children of 25 to 60 month which is comparable with the study conducted by $\mathrm{Km}$ et al where $79 \%$ children were of 6 to 24 months. ${ }^{10}$ The increased incidence of Pneumonia in below 24-month age group can be due to loss of acquired immunity and the fragility of the defense system in the context of contouring and consolidation of the immune status but also of the contact with the environment. In this study, cough, fever and fast breathing were the main symptoms observed in 150 (100\%), 121 (80.7\%) and 102 (68\%) children respectively which is similar to the study conducted by Malla et al where $100 \%, 80.7 \%$ and $68 \%$ children with cough, fever and fast breathing were reported respectively. Similar findings were also seen in the study conducted by $\mathrm{Km}$ et al where cough, fever and fast breathing were reported in $100 \%, 88 \%$ and $79 \%$ children respectively. ${ }^{3,10}$

Among signs, chest indrawing was present in $86.7 \%$ cases in our study, which is similar to the study done by Malla et al and $\mathrm{Km}$ et al where $85.7 \%$ and $63 \%$ children with chest in drawing were reported respectively.

In this study, anemia was present in 102 (68\%) cases which is similar to the study conducted by Rani et al, Malla et al, Hussain et al, Ramkrishna $\mathrm{n}$ et al and Roma et al where the prevalence of anemia was $62.8 \%, 64.5 \%, 74 \%, 68.6 \%$ and $72 \%$ respectively. ${ }^{1,3,11-13}$ Pneumonia exaggerates iron 
deficient erythropoiesis by blocking the release of iron from the storage pools which can be the reason for the occurrence of anemia in pneumonic children.

The mean hemoglobin level was 9. $49 \pm 1.39 \mathrm{gm} / \mathrm{dl}$ which matches with the study conducted by Rani et al $(9.70 \pm 1.89)$ and Rashad et al $(9.5 \pm 1.1 \mathrm{gm} / \mathrm{dl})$. $^{1,14}$

In this study, among the anemic children, $64(62.7 \% 0$ cases were of 6-to-24-month age group with 38 (37.3\%) of 24 to 60 month which is quite comparable with the study conducted by Malla et al and Chandrashekar et al., ${ }^{3,15}$ This age group is more commonly involved due to supplementary and complementary feeding practices that might be inadequate and inappropriate, are practiced and advocated widely in this age group, due to which hemoglobin could touch the nadir. Also it can be due to inadequate iron supply despite a high iron requirement at this age.

In this study, microcytic and hypochromic anemia was present in $73(71.6 \%)$ cases which is comparable to the study done by Rashad et al (63.2\%), Chandrashekar et al $(60 \%)$ and Hussain et al $(78.9 \%){ }^{14-16}$ The most common cause for microcytic and hypochromic anemia is iron deficiency and after 6 month of age, iron stores are depleted and it is the time at which iron demand increases.

Microcytic and hypochromic anemia was diagnosed on the basis of high RDW, low MCV, low MCH and low MCHC which are the findings seen in iron deficiency anemia as well. Serum ferritin level was not done as ferritin level is not reliable in cases with infection as it increases probably as acute phase protein.

\section{REFERENCES}

1. Rani N, Zubair N, Atta HI. Frequency of anemia in children suffering from pneumonia at a tertiary care hospital.J Med, Physiol and Biophys. 2018;41:53-7.ISSN 2422-8427.

2. Mourad S, Rajab M, Alameddine A, Fares M, Ziade F, Merhi BA. Hemoglobin level as a risk factor for lower respiratory tract infections in Lebanese children. N Am J Med Sci. 2010;2(10):461-6. DOI: 10.4297/najms.2010.2461.

3. Malla T, Pathak OK, Malla KK. Is low hemoglobin level a risk factor for acute lower respiratory tract infections?. J Nepal Pediatr Soc. 2010;30:1-7. DOI: 10.3126/jnps.v30i1.2453

4. Asrie F. Prevalence of anemia and its associated factors among pregnant women receiving antenatal care at Aymiba Health Center, northwest Ethiopia. J Blood Med 2017;8:35-40. DOI: 10.2147/JBM.S134932

5. Stepan D, Dop D, MorosanuA,Vintilescu B, Niculescu C. Implications of the iron deficiency in lower tract respiratory acute infections in toddlers. CurrHealthSciJ.2018;44(4):362-7. DOI:10.12865/CHSJ.44.04.07

6. Abdel-Maksoud HM, Hasan KA, Helwa MA. Evaluation of iron deficiency anemia as a predisposing factor in the occurrence of pneumonia in children. Trends Med Res 2016;11:69-75. DOI:10.3923/tmr.2016.69.75

7. Cherayil BJ. Iron and immunity: immunological consequences of iron deficiency and overload.AITE 2010;58(6):407-15. DOI: 10.1007/ s00005-010-0095-9.

8. Garrido D, Fuseau M, Garrido S, Vivas G, Gutiérrez M. Prevalence of anaemia in children diagnosed with pneumonia in a tertiary hospital in Quito, Ecuador. J Nepal Paediatr.Soc. 2018;38(2):102-9. doi:http://dx.doi.org/10.3126/jnps.v38i2.20193

9. Sakellaropoulou A, Hatzistilianou M, Eboriadou M, AthanasiadouPiperopoulou F. Hyponatraemia in cases of children with pneumonia. Arch Med Sci. 2010;6(4):578-83.doi: 10.5114/ aoms.2010.14471.

\section{CONCLUSION}

Increased prevalence of anemia is noted in children below 24 months with pneumonia in our study. While treating childhood pneumonia, anemia is generally neglected so pediatricians must check hemoglobin levels on a routine basis among this targeted population.

\section{RECOMMENDATION}

In the view of high probability of anemia in pneumonic children, screening for anemia on a regular basis needs to be considered.

\section{LIMITATIONS OFSTUDY}

An important limitation to our study is the small number of patients. Our study reflects data from one center only and may not represent that of other centers across the country. Hence, multicenter trials would be necessary to determine the prevalence of anemia in pneumonic children.

\section{ACKNOWLEDGEMENTS}

We highly acknowledge the department of Community Medicine for helping us in the statistical analysis of data.

\section{CONFLICT OF INTEREST}

None

\section{FINANCIAL DISCLOSURE}

None

10. Km R, Gupta V, Ahmad S, Ranhotra S., Issrani R, Prabhu N Assessment of anemia as a risk factor for acute lower respiratory tract infections in children: A case-control study. Int J ClinPediatr. 2015;4(2-3):149-53. doi: http://dx.doi.org/10.14740/ijcp220w

11. HussainSQ,Ashraf M, Wani JG, Ahmed J. Low hemoglobin level a risk factor for acute lower respiratory tract infections in children. J Clin Diagn Res. 2014;8(4):1-3. doi: 10.7860/JCDR/2014/8387. 4268.PMID: 24959486

12. Ramakrishnan K, Harish PS. Hemoglobin level as a risk factor for lower respiratory tract infections. Indian J Pediatr. 2006;73(10):881 3. doi: 10.1007/BF02859279.

13. Roma KM, Gupta V, Ahmad S, Ranhotra S, Issrani R, Prabhu N. Assessment of anemia as a risk factor for acute lower respiratory tract infections in children: a case-control study. Int J ClinPediatr. 2015;4(2-3):149-53. doi: http://dx.doi.org/10.14740/ijcp220w

14. Rashad MM, Fayed SM, El-Hag AMK. Iron-deficiency anemia as a risk factor for pneumonia in children.Benha Med J. 2015;32(2):96-100. DOI: 10.4103/1110-208X.180321

15. Chandrashekar B. Prevalence of microcytic hypochromic anemia in children with LRTI in the age group of 3 months to 5year: Is iron deficiency anemia a risk factor for LRTI?. Pediatric Review: Int J Pediatr Res. 2014; 1(3): 87-92. https://doi.org/10.17511/ ijpr.2014.i03.05

16. Hussain SQ, Ashraf M, Wani JG, Ahmed J. Low hemoglobin level a risk factor for acute lower respiratory tract infections (ALRTI) in children. J Clin Diagn Res. 2014; 8(4) :PC01-PC03. PMID: 24959486. PMCID: PMC4064840. DOI: 10.7860/JCDR/2014/8387.4268 